\title{
Legalization of Cannabis Cultivation a Comparative Study
}

\author{
Samer Hameed Safer ${ }^{1}$ \\ Samer.alrikabi@stu.edu.iq ${ }^{1}$ \\ Nassriyah Technical Institute, Southern Technical University, Iraq ${ }^{1}$
}

\begin{abstract}
Legalizing cannabis cultivation is one of the most important challenges that countries face considering the economic depression that these countries have been suffering from for a long time because of accelerated and unexamined economic policies and because of economic conditions in the Arab and global region, which led to the collapse of the economic systems adopted by countries. This caused a deficit in their budgets for this and that and considering the relentless pursuit of accepting the least loss, these countries began to search for legal solutions through which they could reduce the effects of the financial deficit, and at the same time try to limit negative phenomena by controlling them and trying to control them or lowering it or taming it by legal means.
\end{abstract}

Keywords: Cannabis, Countries, Cultivation, Drug

\section{Introduction}

Legalizing cannabis cultivation is among the most important challenges facing countries in the world considering the economic depression that these countries suffer from for a long period because of accelerated and unexamined economic policies and as a result of the economic conditions in the Arab and global region, which led to the collapse of the economic systems adopted by the countries. Which caused a deficit in their budgets for this and, and in light of the relentless pursuit of accepting the least loss, these countries began looking for legal solutions through which they could reduce the effects of the financial deficit and also at the same time try to limit negative phenomena by controlling them and trying to control, reduce or tame them by legal means, which reflects the prestige of the state. Discussions took place among many jurists in some Arab countries to try to legalize cannabis cultivation or not by confronting two trends. The first is that which supports this project or idea by opening the legislative door wide open to access legalized cannabis in a medical and humane method that aims to protect people instead of eliminating it. According to what is seen by the other side, which has tended to consider that such propositions do not fit with those societies, especially Muslim ones that follow the teachings of Islam, because this is contrary to Sharia and religion and because it undoubtedly leads to the collapse of the human being and society and the spread of corruption among the categories of individuals of those countries, provided that this And that from both directions did not prevent politicians and lawmakers in those countries from serious attempts at the level of adopting legal cannabis for its frequent use in medical fields and industrial purposes, although this would be following controls and procedures taken by those countries to legitimize such a measure and at the same time emphasize the international legal principles agreed upon between states. 
To confront the phenomenon of drugs or to encourage them. The economic conditions that the world suffers from has led to some of those countries attempting to adopt the Western approach by legislating a law that recognizes cannabis and cultivates it in a way that secures a decent life for citizens and limits the increasing spread of the drug phenomenon, or reduces or limits it by legal means [1]. To achieve an economic recovery to adopt the cultivation of hemp and generate revenues from it, in addition to its use by roads According to the legal drivers used in those who used to legalize that material or cultivate it in a way that guarantees the higher values that prevail in it. The rejectionist trend and the trend in favour of legalizing cannabis with all its supporters or opponents formed a fertile ground for the jurists to address such a topic and try to explore its folds neutrally. Who tried to shed light on the legislation that regulated this aspect and to know the extent of the possibility of adopting such a legislative measure or not? It was necessary to adopt the historical approach to describe the previous historical events of countries that adopted such an idea in addition to the comparative approach by comparing the contexts followed in other countries and which implemented this legislative vision or not.

\section{What is Cannabis?}

In this proposal, we try to define cannabis by stating the most important countries in which it has spread and what definitions have dealt with it in medical, legal, and jurisprudential terms. The first requirement introducing cannabis (Cannabis Indica). Hemp is known as the Indian, marijuana, a plant that has a narcotic effect, and it also has effects on the body. One of the most used types of drugs in the world. Hemp products belong to the oldest known drugs, and hemp is, the name of the plant, while marijuana is the leaves, flowers, stems, and dried seeds of the hemp plant, while hashish is another product from the hemp plant that contains gum. (AbdelGhani, 2011, p. 10) Hemp and cannabinoids contain many substances, but the most important one is delta tetrahydrocannabinol, commonly known as THC. When a person smokes marijuana or hashish, THC passes quickly from the lungs into the bloodstream, which carries it to the brain and other organs throughout the body, according to the National Institute of Drug Abuse in the United States and the National Institutes of Health in the US Department of Health. THC acts on specific receptors in brain cells that normally interact with natural chemicals like THC. These natural chemicals play a role in normal brain development and function. Marijuana over-activity in the parts of the brain that contain the largest number of these receptors, and this causes a person to feel euphoric the use of cannabis and its products is addictive, and research indicates that between 9 and $30 \%$ of those who use marijuana may develop some degree of addiction. An Australian scientist warned in 2014 in his published research that cannabis damages the brain and leads to severe addiction, as one out of every six adolescents who use it become addicted, which carries the risk of harm to their brains and doubles their risk of developing schizophrenia, a mental illness. Wayne Hall, professor of addiction policy at London Kings College, a research university in the British capital, said that young people who abuse cannabis do less at school than their peers who do not [2]. They abuse this substance, and those who drive under the influence of cannabis have a double risk of colliding with others. Hall's research, published in Edition magazine, dispels the myth that smoking marijuana is not dangerous and is a safe alternative to cigarettes and hard drugs. Hall - who also heads the University of Queensland's Centre for Research on Young Substance Abuse and Drug Abuse - said it is likely that one in ten regular cannabis smokers will take a stronger drug. He added that the risk of taking stronger drugs rises to one in six young adults who start using cannabis in their teens. On the other hand, there are medical uses for cannabis, in Germany, hemp has been used since 2011 to prepare medical prescriptions based on special permits obtained by the German Institute of Medical Materials and Medicines. Medical 
laboratories prepare medicines mixed with cannabis, which are taken in the form of drops that travel through the mouth and quickly into the patient's blood. Studies show the good effect of cannabis on some diseases. Although it does not completely cure the disease, it reduces the pain intensity and the degree of suffering of the patients [3].

\section{Cannabis Cultivation}

Hemp remains the most widely cultivated drug crop, which was reported by 129 countries over the period 2009-2014, far more than the 49 countries that reported the cultivation of opium poppy. Countries (mostly in Asia and the American continent), and the 7 countries that reported coca cultivation (7 countries) are [4]: (On the American continent). Regardless of the disparity in the number of countries that grow both opium poppies and coca, the cultivation of opium poppy decreased in the past year while the cultivation of coca increased. Cannabis also remains the most popular drug trafficked globally, and there has been a significant increase in seizures of synthetic drugs. Although there were 234 substances under international control in 2014 244 articles in January 2016), the bulk of trafficking (based on drug seizures that embody both law enforcement activities and the flow of drugs) is concentrated in a smaller number. Far from Materials. Cannabis in its various forms was intercepted in 95 percent of reporting countries in 2014 and accounted for more than half of the drug seizures reported to the United Nations Office on Drugs and Crime. The year, with several 2.2 million, is followed by ATS and opioids and substances related to coca. In all countries, more men ( 90 percent of the total, on average) who are formally represented before the criminal justice system for drug trafficking or possession of drugs for personal use exceed the number of women who are for the same reasons. However, the reporting of sex-disaggregated data has improved over the years, and it shows an increase in the number of women arrested for drug-related offenses in absolute numbers. Nevertheless, despite the fluctuation of the proportion of women in drug-related arrests, that percentage moved in a downward trend over the period 1998-2014, particularly related crimes [5]. Despite significant changes in some regions, global consumption of cannabis has remained largely stable in recent years with a noticeable increase in drug users.

\section{The Legal Regulation of Cannabis Cultivation}

The topic deals with the legal regulation of cannabis cultivation in European countries, then in Arab countries, as follows [6]. The issue of drugs and drug addiction is considered one of the living and fundamental issues of concern to the international community as a whole, and perhaps this international interest in this issue is not born today but extends back hundreds of years, and if you wish, then fewer thousands of years, as the ancient Egyptians used cannabis to help them work and produce, as they used Opium (poppy) helped calm hyperactive children, and after that, people used drugs With its different types, whether natural, such as cannabis (hashish) and poppy (opium), and the uses varied between those used in the absence of the mind, loss of balance, and the achievement of false and fleeting ecstasy There is no doubt that the increase in global addiction rates is due, in one way or another, to the weakness of the foundations necessary to curb the illicit trade in narcotic drugs and psychotropic substances, such as the international community or the internal societies of the world countries Hence, the drug problem has become one of the most important problems that the international community is dealing with, whether in the United Nations Organization or the League of Arab States. This is in addition to the efforts made by each country alone or through its bilateral cooperation with 
another country, or multilateral cooperation between countries. The chapter on adherence to international agreements and to make joint efforts in the field of drug control and prevention, to achieve effective control over them, in addition to imposing tight control on cannabis to prevent its leakage for illicit use or the manufacture of narcotic drugs and psychotropic substances [7]. Therefore, we will divide this issue into the regional side in the fight against drugs (hashish) and the local side in this matter. The first requirement is regional organization: The Arab Convention for Combating Illicit Traffic in Narcotic Drugs and Psychotropic Substances was concluded for the year 1994 to strengthen Arab cooperation to address the drug problem in all its aspects. Arab efforts coordinated with international efforts in the field of combating narcotic drugs and psychotropic substances and controlling chemical precursors The Arab anti-drug agencies are as follows [8]:

1. The Council of Arab Interior Ministers: It works under the umbrella of the Arab League, and one of its most important achievements is a - Unified Arab model law for combating drugs that have not yet been implemented.

2. The Arab strategy to combat the illicit use of narcotic drugs and psychotropic substances.

3. The Guiding Model Arab Law for Combating Money Laundering

4. The Guiding Model Arab Law for Combating Drug Crimes Committed via the Internet

The Arab Office for Narcotics Affairs: Coordinates Arab efforts in the field of combating drugs within the framework of the 1994 Arab Agreement to Combat Illicit Traffic in Narcotic Drugs and Psychotropic Substances. The Arab Conference of Heads of Drug Control Agencies and its sub-groups. This conference is held annually and discusses the drug problem in Arab countries and ways to effectively address it. Three sub-working groups are divided into each group, which includes several neighbouring Arab countries with similar actors facing similar solutions to the drug problem. As for the control mechanisms that can be detected through the information and data that have been analysed, it is noted that all countries participating in this project have a department specialized in combating narcotic drugs and psychotropic substances and their trafficking. In most cases, it is a department within the security services of the Ministry of Interior. Where we can attribute the inclination of states to establish this specialized apparatus to the seriousness of the crime of illicit trafficking in narcotic drugs and psychotropic substances and the sheer volume of funds and networks that are used to commit them, which requires a cadre commensurate with this severity and size and specialization in the operations of prosecution, seizure, and evidence, and to provide these entities with the capabilities. The Arab countries had a position rejecting the cultivation and trade of cannabis according to the agreements concluded, and there is almost agreement to prevent this, but some of those countries, in light of the economic developments, began searching for a new source of revenue, including Morocco Where a law was put in place regulating the cultivation of cannabis, and in light of the economic needs, other countries began to demand, by their policies, the enactment of a law to regulate the cultivation of cannabis, including Lebanon, to meet the economic and health situation in the country, As for the Arab Gulf states, they refused that, including Iraq. 


\section{Local Organizations (Iraq)}

Iraq, like other Arab countries, faced the drug problem before 2003, as a statistic of the Ibn Rushd Psychiatric Hospital in Baghdad showed that there were 3 drug addicts out of every 10 individuals in Iraq. Iraqi youth after 2003, according to its reports, and the statistics of the bureau did not record only two cases as drug trafficking only between 1970 and 1990, but after the entry of the American forces into the country, the security course changed dramatically, and imaginary numbers were recorded. This is because the United Nations report showed that out of every ten people between the ages of 18-30 years of age, three are addicted and that one out of every three members of the security forces takes a drug, and the reason for this is the lack of follow-up, awareness and treatment centres, as well as a low penalty rate. As for the present time, the penalty for drug traffickers is approximately 6 months, in addition to the fact that most of the dealers are supported by capable bodies in the state. It reveals that the statistics of outpatient clinics in government hospitals in 2009 indicated that $10 \%$ of the number of addicts to alcohol and psychotropic medicinal pills reached 2017, with about 320 people lying in hospitals [9].

According to the latest statistics of the Supreme National Commission for Drug Control, there are more than 7000 cases of addiction in Iraq, including cases of addiction to narcotic pills. Thus, Dr. Aqil Al-Sabbagh, Director of Mental Health in the Basra Health Department, says, "Narcotic pills were misused by some young people, so they used them as narcotic substances. Cheap and easy to get. " Concerning the Iraqi Narcotics Law issued on 2017, No. 50, we see that it emphasized the criminalization of drugs of all kinds, including hashish, as this law affirmed the establishment of a national body dealing with drugs, which is the Supreme National Authority for Narcotics and Psychotropic Substances in Article (3) of Law No. (50) For the year 2017, it shall be located in the Iraqi Ministry of Health and shall be specialized following the provisions of Article (5) with the following: Setting a general policy for importing any kind of drugs, including production and agriculture, and coordination and cooperation between ministries and competent authorities in this regard. A comprehensive national strategy to combat non-trafficking is also being developed. The drug project and preparing plans and programs for their implementation in the region and governorates that are not organized in a region through local committees that are formed in each governorate and region what is noticeable in the text of the previous article is that it depends on cooperation and coordination, uniting efforts and urging cooperation with civil society organizations to confront this phenomenon, even if that is in return for financial support, but that has not been achieved on the ground, especially about cooperation with civil society organizations, as for what is related to coordination And uniting efforts, this matter is related to the formation of committees that will result in sub-committees that try to achieve that cooperation for the success of this goal, which is the elimination of this phenomenon. The law also stipulated that a directorate shall be established in the Ministry of Interior called (the General Directorate of Narcotic Drugs and Psychotropic Substances) headed by an officer with experience and competence to undertake the following:

"Combating and controlling narcotic substances and cooperating with the Arab Office for Drug Affairs and with its counterparts in other countries and with international and regional bodies specialized in narcotic drugs and psychotropic substances, and with the International Criminal Police Organization (Interpol) about the prosecution of the perpetrators of the crimes of illicit drug trafficking and monitoring the offenders according to this law By importing, exporting, transporting, manufacturing, or possessing narcotic drugs or psychotropic substances to ensure their obligations within the limits of specified controls [10]. 
The law also stipulated that "a police directorate shall be established in each governorate at the level of a department headed by an experienced and competent officer specialized in the affairs of combating narcotic drugs and psychotropic substances. The keenness of the Iraqi legislator to restrict the spread of drugs in Iraq, but in light of the Iraqi legislative developments, which are among the most important of them Preventing the import, sale, circulation, and manufacture of alcoholic beverages, as this would encourage the spread of drugs that could be obtained from pharmacies in light of the chaos in some cities or the lack of control over the work of pharmacies despite the tightening of the Narcotic Law No. 50 of 2017 on how to sell narcotic substances by pharmacists, However, reality indicates the opposite of these measures, They are supposed to be available to achieve this cooperation between the government, pharmacists, doctors, stores and all the authorities working in nursing to prevent the spread of drugs of all kinds [11]. Through studying the law, it becomes clear to us that the Iraqi legislator has explicitly stated in the text of Article (23) thereof that it is not permissible to cultivate, import, export, possess, acquire, possess, purchase, sell, transfer, deliver, exchange, or assign plants that are produced. They contain narcotic drugs or psychotropic substances stipulated in the first schedule attached to this law in all stages of their growth, their seeds, exchange with them, or mediating anything of that except for medical or scientific purposes and in the circumstances the conditions stipulated in this law and the circumstances. Coca, khat, and plants that contain this are genetically modified, which have the same effect as the drug. As for the second chapter, the law dealt with penalties, including the text of Article (27) thereof (punishable by death or life imprisonment) whoever commits one of the following acts: Third: He planted a plant that produces narcotic substances or $\mathrm{m}$ ) mental wealth, or imports or brings or export a plant of these plants at any stage of their growth to trade them or trade their seeds in other than the cases permitted by law)

\section{Conclusion}

Through the previous presentation, it becomes clear to us that the Arab countries have tried to cooperate to combat the phenomenon of the spread of hashish or cultivation, but the reality is now, and in light of the austerity that most Arab countries are experiencing, some of them have begun trying to find sources of public income by trying to ask the legislative authority to legalize A law permitting the trade in cannabis or cultivation, provided that the purpose of that is a medical purpose or personal possession, as is the case in Lebanon, which has begun trying to legalize this. Also, Egypt has raised voices while calling for the legalization of cannabisbased on the financial returns that result from cultivating or trading it that It was via the legitimate routes in the country; This case, which we presented in the last lines, is true, as it represents a major development in politics This would lead some to demand a law to allow prostitution or law to allow the arms trade.

The most important results we reached:

1. Many Arab countries considered the cultivation of hemp, especially medical hemp, among the most important financial resources that could be relied upon in the future to advance the economic reality of developing countries.

2. The Arab countries varied among themselves in this regard, some of them accepted the idea and accepted it, and some rejected it under the pretext of promoting drugs. 
3. Some of the Arab countries have accepted this idea and accepted it as a fait accompli.

4. Others, and the other side of the world, rejected this idea but went so far as to criminalize such topics as they are contrary to what is stipulated in their constitution.

Through the previous results, we conclude the following:

1. There is no doubt that the acceptance of drug cultivation constitutes a precedent that is unknown in the countries of the Arab world, which means taking risks or accepting to proceed in contrast to the legislative policy of those countries.

2. The countries that accepted this idea and went to legalize it are considered countries that are more civilized and accepting of democracy, even if entering this field came as a matter of therapeutic purposes.

3. Acceptance of cannabis cultivation will lead to the spread of drugs in countries of the world or especially in the country that adopts agriculture in its laws, and this has both positive and negative aspects. The positive aspects are the elimination of the illegal trade of such acts and an attempt to legitimize those actions. The negative answer is that. This is represented by the spread of the drug phenomenon, which entails the spread of illegal trade in addition to the proliferation of weapons, which leads to crimes that devastate people.

4. We may find other countries join the list of countries that support the idea of growing or trading hemp in the future in light of the difficult economic conditions that are suffering, especially in light of the Corona epidemic.

\section{References}

[1] Weybright EH, Caldwell LL, Xie H, Wegner L, Smith EA. Predicting secondary school dropout among south african adolescents: A survival analysis approach. South African journal of education. 2017;37(2):1-11.

[2] Adinoff B, Reiman A. Implementing social justice in the transition from illicit to legal cannabis. The American journal of drug and alcohol abuse. 2019;45(6):673-88.

[3] Bodwitch H, Carah J, Daane K, Getz C, Grantham T, Hickey G, et al. Growers say cannabis legalization excludes small growers, supports illicit markets, undermines local economies. California Agriculture. 2019;73(3):177-84.

[4] Dei Cas M, Casagni E, Saccardo A, Arnoldi S, Young C, Scotti S, et al. The italian panorama of cannabis light preparation: Determination of cannabinoids by lc-uv. Forensic science international. 2020;307:110113.

[5] El-Khoury J, Bou Khalil R, Nemer A, Richa S. Legalizing medical cannabis in lebanon: The complex interface between medicine, law, ethics, and economics. Cannabis and Cannabinoid Research. 2020.

[6] Feinstein BA, Dyar C, London B. Are outness and community involvement risk or protective factors for alcohol and drug abuse among sexual minority women? Archives of Sexual Behavior. 2017;46(5):1411-23.

[7] Luo X, Reiter MA, d'Espaux L, Wong J, Denby CM, Lechner A, et al. Complete biosynthesis of cannabinoids and their unnatural analogues in yeast. Nature. 2019;567(7746):123-6.

[8] Muchiri BW, Dos Santos MM. Family management risk and protective factors for adolescent substance use in south africa. Substance abuse treatment, prevention, and policy. 2018;13(1):1-10. 
[9] Nurzyńska A. International cooperation in combating organized crime. World Scientific News. 2018;106:105-16.

[10] Omelchuk O, Shekhovtsova L, Bodunova O, Lukasevych-Krutnyk I, Yanishevska K, Plutytska K. Criminal-legal and criminological research of illicit trafficking in narcotic drugs and their analogues with the use of computer technologies. International Journal of Management (IJM). 2020;11(6).

[11] Wang Z, Yang X, Zhang X. Relationships among boredom proneness, sensation seeking and smartphone addiction among chinese college students: Mediating roles of pastime, flow experience and self-regulation. Technology in Society. 2020;62:101319. 